\title{
A PRESENÇA DA EDUCAÇÃO INFANTIL EM COMPONENTES OBRIGATÓRIOS DE EDUCAÇÃO MATEMÁTICA EM CURSOS DE PEDAGOGIA NAS UNIVERSIDADES FEDERAIS DO SUL DO BRASIL
}

\author{
THE PRESENCE OF CHILDHOOD EDUCATION IN MANDATORY COMPONENTS OF MATHEMATICAL \\ EDUCATION IN PEDAGOGY COURSES AT FEDERAL UNIVERSITIES IN SOUTHERN BRAZIL
}

JOÃO CARLOS PEREIRA DE MORAES ${ }^{1}$

\section{RESUMO}

Atualmente, os estudos sobre Formação de professores que ensinam Matemática adquiriram relevância na Educação Matemática. Contudo, os números de investigações preocupadas com a Educação Infantil ainda são incipientes. Perante 0 citado, esta pesquisa objetiva analisar a relação de componentes curriculares obrigatórios de Educação Matemática em cursos de Pedagogia presenciais das Universidades Federais da Região Sul do país com o debate sobre Educação Infantil. Para tanto, levantou-se componentes curriculares de Educação Matemática relacionadas com Educação Infantil nos Projetos Pedagógicos dos Cursos de Pedagogia das universidades em questão. Tais componentes foram considerados documentos de análise, o que permitiu um processo analítico em duas fases: contextuais e específico. Como resultado, nota-se o foco na ludicidade e psicologia da aprendizagem, bem como ausências do estudo documentos oficiais. Com o estudo, concluiu-se que nos futuros processos de construções de componentes de Educação Matemática na Pedagogia é necessário repensar a relevância dada para a Educação Infantil.

Palavras-chave: Educação Matemática. Educação Infantil. Pedagogia. Formação Inicial. Projeto Pedagógico de Curso.

\section{ABSTRACT}

Currently, studies on Teacher Education that teach Mathematics have acquired relevance in Mathematics Education. However, the numbers of investigations concerned with early childhood education are still incipient. In view of the aforementioned, this research aims to analyze the list of compulsory curriculum components of Mathematical Education in classroom Pedagogy courses at Federal Universities in the southern region of the country with the debate on Early Childhood Education. To this end, curriculum components of Mathematical Education related to Early Childhood Education were raised in the Pedagogical Projects of the Pedagogy Courses of the universities in question. Such components were considered analysis documents, which allowed an analytical process in two phases: contextual and specific. As a result, there is a focus on playfulness and learning psychology, as well as absences from the study official documents. With the study, it was concluded that in the future processes of construction of components of Mathematical Education in Pedagogy it is necessary to rethink the relevance given to Early Childhood Education.

Keywords: Mathematical Education. Child education. Pedagogy. Initial formation. Pedagogical Course Project.

\footnotetext{
1 Doutor em Educação (USP). Professor e pesquisador no Programa de Pós-Graduação em Educação (UNIPAMPA) e no Programa de Pós-Graduação em Ensino de Ciências e Educação Matemática (UEPG). Titulação. E-mail: joaomoraes@unipampa.edu.br. Orcid: https://orcid.org/ 0000-0001-9513-018X
} 


\section{INTRODUÇÃO}

Ao longo dos últimos anos, discussões sobre a Formação de Docentes que ensinam Matemática adquiriram relevantes ganhos qualitativos em suas teorizações, bem como crescimento numérico expressivo de pesquisas. Esse processo consolida-se, por exemplo, no Grupo de Trabalho 01 Matemática na Educação Infantil e Anos Iniciais do Ensino Fundamental, da Sociedade Brasileira de Educação Matemática (SBEM).

As intenções do GT01 caminham para discutir o ensino e aprendizagem da Matemática na Educação Infantil e nos Anos Iniciais do Ensino Fundamental. No entanto, ao ingressarmos na própria discussão dos focos do GT, percebemos ainda ausências ao que tange Educação Infantil em comparação ao debate proposto para os Anos Iniciais do Ensino Fundamental. Conforme o site da SBEM, os focos são:

a) formação inicial e continuada de professores de anos iniciais de escolarização;

b) conhecimento de estudantes, deste nível de ensino, de conceitos matemáticos desenvolvidos dentro e fora da sala de aula; c) recursos didáticos para 0 ensino de Matemática na Educação Infantil e anos iniciais do Ensino Fundamental; d) inclusão e aprendizado de Matemática nestes anos de ensino (SBEM, grifos nossos)

Na citação elencada, a Educação Infantil encontra-se em menor destaque em relação aos Anos Iniciais, surgindo uma única vez e, ainda, associada ao outro nível de ensino. Nesse sentido, um olhar apurado sobre a presença da Educação Infantil no campo da Educação Matemática necessita ser potencializado. Como ponto de partida de investigação², os ementários de Projeto Político Pedagógico (PPC) de cursos de Pedagogia da região Sul do país foram escolhidos para objeto de análise. Deste modo, essa pesquisa visa analisar a relação de componentes curriculares obrigatórios de Educação Matemática em cursos de Pedagogia presenciais das Universidades Federais da Região Sul do país com 0 debate sobre Educação Infantil.

Para tanto, 0 artigo foi subdivido do seguinte modo: (1) Formação de Docentes que ensinam Matemática; (2) Pressupostos curriculares de Matemática na Educação Infantil; (3) Aspectos metodológicos da pesquisa; (4) Resultados e Discussões desenvolvidos nos estudos; e, por fim, as (5) Considerações Finais da pesquisa.

\section{FORMAÇÃO DE DOCENTES QUE ENSINAM MATEMÁTICA}

Historicamente, o professor que almejamos ser e formar transformou-se. Fiorentini (1994), nesse sentido, analisando as pesquisa e intervenções no tema, descreveu o processo histórico dos últimos sessenta anos em relação ao assunto. 0 autor ressalta que os estudos focalizaram desde a eficácia de diferentes métodos para treinar professores em tarefas específicas (década de 1970), 0 pensamento do professor e a sua influência sobre seu desenvolvimento cognitivo e moral (início da década de 1980), coexistência da visão de ensino como arte e ensino como profissão (segunda metade da década de 1980) e análise de crenças, concepções e seus valores docentes (década de 1990).

No entanto, da década de 1990 para cá, tem ganhado força autores que discutem uma epistemologia da prática para a formação docente (TARDIF, 2002; SCHÖN, 2000; PERRENOUD, 1999;

\footnotetext{
2 Este artigo compõe os resultados do Projeto de Pesquisa "Formação Docente, Infância e o Ensino das Ciências: dos constructos teóricos às práticas educacionais" (UNIPAMPA) e baliza-se com os estudos realizados no InfanSCientia - Grupo de Estudos e Pesquisas em Infância, Cultura e Ensino das Ciências (UNIPAMPA).
} 
SCHULMAN, 1987), em que se priorizam a reflexão e discussão sobre práticas docentes, analisando os saberes provenientes da mesma. De modo geral e sintético, podemos dizer que esses autores questionam 0 academicismo exacerbado de alguns modelos de formação docente e a pouca inserção prática dos discursos e elaborações teóricas do campo educacional.

Tardif (2002), por exemplo, ressalta a necessidade de pensar o docente como um profissional composto por saberes. Para 0 autor, o saber docente define-se como um "saber plural, formado de diversos saberes provenientes das instituições de formação, da formação profissional, dos currículos e da prática cotidiana" (TARDIF, 2002, p. 54). Isto é, o saber docente consiste numa amálgama de diversos outros saberes, que, em sua combinação, formam o sujeito professor e estipulam as suas práticas.

Deste modo, como dito anteriormente, 0 saber docente pressupõe configurações que ultrapassam a dimensão do conhecimento do conteúdo da disciplina, alcançando um patamar de saber reflexivo, plural e complexo, contextual, afetivo e cultural (FIORENTINI, 1994). Por essas características, não se torna válido considera-lo conhecimento enrijecido e estagnado, mas lócus de mudança e transformação. Entre fatores que possibilitam essa mutabilidade está a sua constituição volátil, mediada pela trajetória profissional docente e pelas interações com 0 ambiente de sala de aula.

Por esse motivo, Perrenoud (1999) considera o conhecimento do professor como um conhecimento na ação, em que é possível a partir dele mobilizar diversos recursos cognitivos para enfrentar as situações profissionais que surgirem. Tais situações, também, como ressalta Villani e Pacca (1997), são as possibilidades de o professor elaborar e reelaborar seu conhecimento, transformando-0. Ser docente em formação, então, consistiria entrar neste ciclo de reflexão e produção de conhecimento por meio da prática, capaz de criar alternativas de ação frente ao contexto escolar.

Donald Schön (2000), outro pesquisador preocupado com a prática no processo formativo docente, corrobora tal perspectiva. Suas pesquisas ressaltam que o professor mostra seu conhecimento na realização da ação, podendo esta ser o foco de intervenções no processo de formação. Para os futuros professores, este saber de ação pode ser compreendido nas vivências do espaço escolar. Para eles, o conhecimento da ação são olhares reflexivos sobre professores que tiveram na Educação Básica, os estágios enfrentados ou, ainda, aulas eventuais. Embora pareçam experiências pequenas, são esses os espaços que teoria e prática encontram-se na formação inicial.

Paralelo à relação com a prática, Shulman (1987) procura compreender como um professor se diferencia de um especialista de uma determinada disciplina. Isto é, como um professor de Matemática se distingue de um matemático, por exemplo. Para compor sua teorização, ele ressalta três categorias de conteúdos que compõe o trabalho do professor:

- Conhecimento do Conteúdo, que consiste no saber do conteúdo disciplinar em si.

- Conhecimento Pedagógico, que é relativo a questões pedagógicas gerais do campo escolar (currículo, sequências didáticas, avaliações etc.)

- Conhecimento Pedagógico do Conteúdo, que se encontra na intersecção das demais e está localizado no âmbito das práticas de ensino de saberes específicos.

Nesse sentido, 0 debate sobre a formação inicial do professor que leciona para a infância precisa permear o olhar para a construção de sua própria prática, abandonando modelos pré-prontos de atuação ou a imposição de certos modos de ação. Sendo assim, a formação do professor que ensina na Educação Infantil configurar-se-ia como detentora de multiplicidade de saberes. Elemento que nos leva a não pensar uma formação matemática a tal grupo, mas uma formação que também seja matemática para esses sujeitos e que possibilite apropriar-se deste campo disciplinar para produzir intervenções que caminhem ao encontro do ideário de formação de cidadãos. 
Para um debate consonante à perspectiva da epistemologia da prática, torna-se necessário que a discussão seja acompanhada e respaldada por paradigmas conscientes de qual Infância falamos e das necessidades curriculares de Educação Matemática para Educação Infantil. Na seção que segue, apresentamos nossas considerações sobre esse debate.

\section{PRESSUPOSTOS CURRICULARES DE MATEMÁTICA DA EDUCAÇÃO INFANTIL}

Quanto ao paradigma de Infância, ao longo da história da humanidade pode-se observar uma diversidade de compreensões (ARIĖS, 1978; ZABALZA, 1998; KRAMER, 2003), o que nos leva a considerar que 0 conceito de infância é situado no momento histórico e cultural, podendo, assim, ser modificado e/ou problematizado pelos estudiosos da área. Nesse sentido, o conceito supracitado confunde-se com o "sentimento de infância" (ARIÈS, 1978), ou seja, com a consciência da sociedade que a infância possui particularidades que a distingue de outros momentos da vida humana, o que implica formas diferenciadas de tratamento.

Se fizermos um recorte a partir da Idade Média até o século XVII, Ariès (1978) mostra que a criança era percebida como um adulto em miniatura, já a infância não possuía parâmetros de idade definidos. A partir do momento que a criança torna-se capaz de realizar uma tarefa, mesmo que precariamente, ela é inserida no mundo das responsabilidades adultas. Associado a isso, encontramos a pouquíssima preocupação com a saúde dos pequenos, uma vez que, embora a mortalidade infantil fosse altíssima, a natalidade também 0 era. Assim, a sociedade acabava vivendo num processo de compensação.

Nos séculos XVIII e XIX, entra em ação o papel das instituições. Em primeiro momento aquelas de cunho religioso, para atender as crianças colocadas nas "rodas expostas", geralmente abandonadas por famílias tradicionais (ZABALZA, 1998). No segundo plano, emerge iniciativas isoladas para criação de creches, asilos ou internatos, que eram destinados para crianças provenientes de famílias pobres. Nessa configuração, pode-se dizer que 0 sentimento de infância pauta-se na assistência social e, mesmo que timidamente, num processo de proteção à criança. Já no final do século XIX e início do XX, o ideário de construção de uma nação moderna corroborou as primeiras tentativas educacionais para 0 grupo, considerando-as o futuro da nação (ARIĖS, 1978). A este período é possível associar a criação dos jardins-de-infância, inspirados nas ideias de Froebel (KRAMER, 2003).

Atualmente, a ideia de infância está associada em grande parte com a compreensão de futuro. Nessa perspectiva, cabe aos espaços institucionais elaborar modos de incutir valores e saberes nas práticas educacionais necessários, na concepção da sociedade, para formação de cidadãos participativos e capazes de gerir e melhorar a humanidade.

Outra compreensão de infância que ressaltamos e que tem nos mostrado mais interessante para pensar a sua relação com a Educação Matemática consiste na relação infância-experiência (AGAMBEN, 2001; KOHAN, 2004). Nesta perspectiva, a infância não se caracteriza necessariamente como etapa da vida, mas como uma condição da experiência humana. Nesse sentido, somente na condição de infantes é que certas experiências de mundo nos é possibilitada, nos é permitida. Não nos cabe então antecipar saberes matemáticos de níveis mais avançados, por exemplo, para crianças pequenas. Se assim o fizéssemos, perderíamos a oportunidade de explorar e deixar que 0 sujeito explore as experiências que só são possíveis no momento de Infância.

Ao adentrarmos as questões relativas ao currículo para a Infância, apontamos três documentos: as Diretrizes Curriculares Nacionais de Educação Infantil - DCNEI (2009), Referencial Curricular 
Nacional para a Educação Infantil - RCNEl (BRASIL, 1998) e Base Nacional Curricular Comum - BNCC (BRASIL, 2017).

De acordo com as DCNEl (BRASIL, 2009), em seu artigo 9ª a Educação Infantil possui como eixos estruturantes das práticas pedagógicas as interações e a brincadeira. 0 pressuposto que baliza tais eixos está na relação com o outro para a construção de aprendizagens. No encontro com o outro, 0 sujeito diversifica seu pensamento e modos de ver e viver o mundo.

Frente esses eixos, o RCNEI (BRASIL, 1998) e a BNCC (BRASIL, 2017) se constituem. Nesse sentido, o RCNEl propõe o Fazer Matemática como um ato de relação e produção com o outro.

Fazer Matemática é expor ideias próprias, escutar a dos outros, formular e comunicar procedimentos de resolução de problemas, confrontar, argumentar e procurar validar seu ponto de vista, antecipar resultados de experiências não realizadas, aceitar erros, buscar dados que faltam para resolver problemas, entre outras coisas. Dessa forma as crianças poderão tomar decisões, agindo como produtoras de conhecimento e não apenas executoras de instruções (BRASIL, 1998, p. 207).

Com isso, nota-se que as intenções que se formulam caminham para a construção de uma atitude matemática, promovendo modos matemáticos de pensar, compreender, intervir e comunicar a realidade. Para este encontro com a realidade, 0 documento destaca a situação-problema como lócus da realidade. Assim, "a Matemática tem-se caracterizado como uma atividade de resolução de problemas de diferentes tipos. A instituição de Educação Infantil poderá constituir um contexto favorável para propiciar a exploração de situações-problema" (BRASIL, 1998, p. 211). Nesse contexto, as problematizações da realidade se consolidam no cotidiano de jogos e brincadeiras presentes e comuns à infância. A partir de tais práticas, as crianças atribuem significados e estabelecem relações.

No que se refere aos conteúdos, podemos ressaltar a ênfase dada para 0 grupo de crianças de 4 e 5 anos de idade. Para a faixa etária, o documento apresenta três blocos de conteúdos: (1) Números e sistema de numeração; (2) Grandezas e Medidas; e (3) Espaço e Forma. Estes blocos assemelham-se às propostas dos Parâmetros Curriculares Nacionais - PCN (BRASIL, 1997), permitindo-nos compreender um processo de integração e continuidade entre Educação Infantil e Anos Iniciais do Ensino Fundamental.

A partir da segunda metade da década de 2010, emergem os estudos da BNCC, abrangendo incursões para o currículo de Educação Infantil. Seguindo os eixos estruturantes das DCN já apresentados anteriormente, a BNCC apresenta seis direitos de aprendizagem e desenvolvimento para a formação da criança: Conviver, Brincar, Participar, Explorar, Expressar, Conhecer-se. De modo geral, os verbos descritos reforçam a interação. Eles exigem a relação com o outro (conviver, brincar), com o mundo (participar, explorar) e consigo mesmo (expressar, conhecer-se).

No documento, os direitos de aprendizagem e desenvolvimento desdobram-se em cinco campos de experiência (BRASIL, 2017):

1. 0 eu, 0 outro e o nós;

2. Corpo, gestos e movimentos;

3. Traços, sons, cores e formas;

4. Escuta, fala, pensamento e imaginação;

5. Espaços, tempos, quantidades, relações e transformações. 
Embora a BNCC de Educação Infantil não intenta configurar campos disciplinares, podemos concentrar os saberes matemáticos no último campo: Espaços, tempos, quantidades, relações e transformações. Isso não nega a existência de modos de fazer matemática em outros campos, mas elenca a compreensão que o quinto campo reúne as maiores possibilidades de práticas matemáticas.

Ao longo da descrição deste campo são apontados indícios que corrobora as afirmações anteriores:

As crianças [...] procuram se situar em diversos espaços (rua, bairro, cidade etc.) e tempos (dia e noite; hoje, ontem e amanhã etc.). [...] as crianças também se deparam, frequentemente, com conhecimentos matemáticos (contagem, ordenação, relações entre quantidades, dimensões, medidas, comparação de pesos e de comprimentos, avaliação de distâncias, reconhecimento de formas geométricas, conhecimento e reconhecimento de numerais cardinais e ordinais etc.) que igualmente aguçam a curiosidade (BRASIL, 2017, p. 42-43)

Na BNCC ainda são demarcados objetivos de aprendizagem e desenvolvimento por faixa etária. Nesse Documento, elaborou-se três grupos, os bebês (zero a 1 ano e 6 meses), crianças bem pequenas (1 ano e 7 meses a 3 anos e 11 meses) e crianças pequenas (4 anos a 5 anos e 11 meses). Essa subdivisão associa-se a processos de desenvolvimento da criança e as possibilidades de intervenção passíveis de ser realizadas pelo o educador como estímulo.

0 documento apresenta uma síntese das aprendizagens para a Educação Infantil no campo de experiências Espaço, tempos, quantidades, relações e transformações:

- Espaços, tempos, quantidades, relações e transformações

- Identificar, nomear adequadamente e comparar as propriedades dos objetos, estabelecendo relações entre eles.

- Interagir com o meio ambiente e com fenômenos naturais ou artificiais, demonstrando curiosidade e cuidado com relação a eles.

- Utilizar vocabulário relativo às noções de grandeza (maior, menor, igual etc.), espaço (dentro e fora) e medidas (comprido, curto, grosso, fino) como meio de comunicação de suas experiências.

- Utilizar unidades de medida (dia e noite; dias, semanas, meses e ano) e noções de tempo (presente, passado e futuro; antes, agora e depois), para responder a necessidades e questões do cotidiano.

- Identificar e registrar quantidades por meio de diferentes formas de representação (contagens, desenhos, símbolos, escrita de números, organização de gráficos básicos etc.) (BRASIL, 2017, p. 55)

Desta síntese, alguns conceitos matemáticos começam a sobressair (tempo, espaço, grandezas, quantidades etc.). No entanto, as discussões não vão ao encontro de uma perspectiva rígida de conteúdos a serem formalizados, mas para aproximações e explorações de noções matemáticas, 0 que permite a ideia de elemento em constante movimento de produção.

\section{ASPECTOS METODOLÓGICOS}

Perante 0 objetivo da pesquisa, analisar a relação de componentes curriculares obrigatórios de Educação Matemática em cursos de Pedagogia presenciais das Universidades Federais da Região 
Sul do país com o debate sobre Educação Infantil, a abordagem metodológica constituiu-se como qualitativa, mais especificamente uma análise documental. Consideramos a pertinência da análise documental na condição de "buscar identificar informações factuais nos documentos a partir de questões e hipóteses de interesse" (CAULLEY apud LÜDKE; ANDRE, 1986, p. 38).

Nesse sentido, definimos os ementários das disciplinas obrigatórias de Educação Matemática nos cursos de pedagogia em questão como documentos, ou seja, um "suporte que contem informação registrada, formando uma unidade, que possa servir para consulta, estudo ou prova" (APPOLINÁRIO, 2009, p. 67). Portanto, é válido ressaltar que os PPC ingressam no processo como contexto, o lócus de inserção dos documentos. Tal fato não os significam quanto vazios para análise, mas relevantes na associação com o documento em questão.

Para a coleta de dados, realizou-se a consulta aos sites das Universidades Federais da Região Sul do país, o que culminou em 11 (onze) instituições. Destas, 3 (três) não apresentam curso de Pedagogia no seu rol de graduações e 1 (uma) possui em três campi diferentes. Sendo assim, em primeiro momento, levantou-se 10 cursos de Pedagogia, caracterizados pela sigla unidade da federação em que estão inseridos (PR, SC ou RS) e um numeral com a finalidade organizacional. Para exemplo, SC2 representa o segundo curso investigado de Santa Catarina. Essa nomenclatura resultou nos seguintes cursos: PR1, PR2, SC1, SC2, RS1, RS2, RS3, RS4, RS5, RS6.

Quanto aos procedimentos, a elaboração compreendeu duas fases. Na primeira, apontou-se para as questões contextuais vigentes, um olhar mais flutuante sobre os PPC dos cursos. Essa análise pautou-se nos seguintes elementos: ano de construção do PPC; 0 rol de disciplinas obrigatórias no campo da Educação Matemática, priorizando localização na grade curricular e cargas horárias (teórica e prática); o rol de disciplinas eletivas e, ainda, a presença de laboratórios e/ou práticas de Educação Matemática.

Já a segunda fase ocorreu especificamente sobre os componentes curriculares de Educação Matemática com apontamentos de Educação Infantil (EMEI). Para esses fora utilizado: indícios presentes em suas nomenclaturas, carga horária (prática e teórica), indicativos provenientes dos ementários e das referências bibliográficas elencadas e relações com componentes de Educação Infantil e/ ou Prática de Estágio nessa etapa da Educação Básica.

0 processo apontado nos procedimentos serviu de base para a construção das análises dos dados. Isto é, a análise foi constituída apontando as duas fases anteriores, privilegiando aspectos mais descritivos do processo.

\section{RESULTADOS E DISCUSSÕES}

A apresentação e análise dos resultados aconteceram em duas etapas. Enquanto na primeira fase são discutidos elementos contextuais aos componentes curriculares de EMEI, na segunda debatem-se os componentes de EMEl em si.

\section{Fase 1: Questões contextuais}

Todos os Projetos Pedagógicos de Curso (PPC) analisados relatam que foram elaborados a partir de um processo democrático e participativo de debate. Isto nos permite considerar que os PPC representam, mesmo que momentâneo, os interesses do corpo docente sobre a formação inicial dos futuros pedagogos. Nesse sentido, importa-se datar as suas constituições, como na Tabela 1 a seguir. 
Tabela 1 - Ano dos PPC.

\begin{tabular}{cc}
\hline PPC & Ano do PPC \\
\hline PR1 & 2018 \\
\hline PR2 & 2018 \\
\hline SC1 & 2009 \\
\hline SC2 & 2019 \\
\hline RS1 & 2018 \\
\hline RS2 & 2019 \\
\hline RS3 & 2018 \\
\hline RS4 & 2012 \\
\hline RS5 & 2018 \\
\hline RS6 & 2015 \\
\hline Fonte: construção do autor.
\end{tabular}

A partir da Tabela 1, nota-se que a maioria dos cursos passou por reformulações nos últimos dois anos, 2018-2019 (PR1, PR2, SC2, RS1, RS2, RS3, RS4). Tais PPC possuem aproximações e entendimentos das Diretrizes Curriculares Nacionais para a formação inicial em nível superior de 2015 (BRASIL, 2015), bem como de algumas alterações nelas realizadas. Não há indícios da Base Nacional Comum para a Formação Inicial e Continuada de Professores da Educação Básica - BNC-Formaçã̃o (BRASIL, 2019), tanto pela atualidade do documento quanto pelas discussões políticas e ideológicas que 0 envolvem. Nesse sentido, entendemos a provisoriedade dos resultados aqui apresentados, uma vez que possivelmente deva existir um processo de reorganização dos cursos de Pedagogia nos próximos anos frente às obrigatoriedades instituídas.

Ao adentrarmos os PPC, elencamos o rol dos Componentes Curriculares Obrigatórios (CCO) de Educação Matemática, sua localização semestral no curso (SEM) e sua carga horária (CH), teórica (CHT) e prática (CHP). Aqueles que consideramos vinculados com a Educação Infantil, apresentamos em itálico na tabela 2.

Tabela 2 - Componentes Curriculares Obrigatórios de Educação Matemática.

\begin{tabular}{|c|c|c|c|c|c|c|}
\hline PPC & $\mathrm{CCO}^{1}$ & SEM & $\mathrm{CH}$ & СHT & CHP & CH total \\
\hline PR1 & $\begin{array}{l}\text { Fundamentos teórico-metodológicos do Ensino da matemática na educação } \\
\text { infantil e anos iniciais do ensino fundamental }\end{array}$ & $5^{0}$ & $60 \mathrm{~h}$ & $60 \mathrm{~h}$ & Oh & $60 \mathrm{~h}$ \\
\hline PR2 & Metodologia do Ensino da Matemática & $5^{0}$ & $30 \mathrm{~h}$ & $30 \mathrm{~h}$ & Oh & $30 \mathrm{~h}$ \\
\hline \multirow{2}{*}{ SC1 } & Educação Matemática e Infância & $4^{0}$ & $72 \mathrm{~h}$ & $72 \mathrm{~h}$ & Oh & \multirow{2}{*}{$144 \mathrm{~h}$} \\
\hline & Fundamentos e metodologia da Matemática & $5^{0}$ & $72 \mathrm{~h}$ & $72 \mathrm{~h}$ & Oh & \\
\hline \multirow{2}{*}{ SC2 } & Matemática na infância I & $7^{0}$ & $30 \mathrm{~h}$ & $30 \mathrm{~h}$ & Oh & \multirow{2}{*}{$75 \mathrm{~h}$} \\
\hline & Matemática na infância II & $8^{0}$ & $45 h$ & $30 \mathrm{~h}$ & $15 h^{2}$ & \\
\hline \multirow{2}{*}{ RS1 } & Ensino de matemática I & $5^{0}$ & $60 \mathrm{~h}$ & $50 \mathrm{~h}$ & $10 \mathrm{~h}^{2}$ & \multirow{2}{*}{$120 \mathrm{~h}$} \\
\hline & Ensino de matemática I & $6^{0}$ & $60 \mathrm{~h}$ & $45 h$ & $15 h^{2}$ & \\
\hline \multirow{2}{*}{ RS2 } & Educação Matemática A & $5^{0}$ & $60 \mathrm{~h}$ & $45 h$ & $15 \mathrm{~h}$ & \multirow{2}{*}{$120 \mathrm{~h}$} \\
\hline & Educação Matemática B & $6^{0}$ & $60 \mathrm{~h}$ & $45 h$ & $15 h$ & \\
\hline
\end{tabular}




\begin{tabular}{|c|c|c|c|c|c|c|}
\hline \multirow{2}{*}{ RS3 } & Educação Matemática I - A & $5^{0}$ & $75 h$ & $50 \mathrm{~h}$ & $25 \mathrm{~h}$ & \multirow{2}{*}{$120 \mathrm{~h}$} \\
\hline & Educação Matemática II - A & $6^{0}$ & $45 h$ & $30 \mathrm{~h}$ & $15 \mathrm{~h}$ & \\
\hline \multirow{3}{*}{ RS4 } & Teoria e Prática Pedagógica VI & $6^{0}$ & $75 \mathrm{~h}$ & $45 h$ & $30 \mathrm{~h}$ & \multirow{3}{*}{$195 \mathrm{~h}$} \\
\hline & Ensino-Aprendizagem, conhecimento e escolarização IV & $4^{0}$ & $60 \mathrm{~h}$ & $60 \mathrm{~h}$ & Oh & \\
\hline & Ensino-Aprendizagem, conhecimento e escolarização II & $2^{0}$ & $60 \mathrm{~h}$ & $60 \mathrm{~h}$ & Oh & \\
\hline \multirow{2}{*}{ RS5 } & Metodologia do ensino em Matemática para crianças, jovens e adultos I & $5^{0}$ & $30 \mathrm{~h}$ & $30 \mathrm{~h}$ & Oh & \multirow{2}{*}{$90 \mathrm{~h}$} \\
\hline & Metodologia do ensino em Matemática para crianças, jovens e adultos II & $6^{0}$ & $60 \mathrm{~h}$ & $60 \mathrm{~h}$ & Oh & \\
\hline \multirow{2}{*}{ RS6 } & Ensinar e Aprender Matemática I & $6^{0}$ & $60 \mathrm{~h}$ & $45 h$ & $15 h$ & \multirow{2}{*}{$120 \mathrm{~h}$} \\
\hline & Ensinar e Aprender Matemática II & $7^{0}$ & $60 \mathrm{~h}$ & $45 \mathrm{~h}$ & $15 \mathrm{~h}$ & \\
\hline
\end{tabular}

\footnotetext{
${ }^{1} \mathrm{CCO}$ relacionados com a Educação estão em itálico.

${ }^{2}$ Carga horária em Prática como Componente Curricular.

Fonte: Construção dos autores.
}

De maneira mais abrangente, observa-se que os PPC apresentam uma carga horária total, em média, entre 100 e 200 horas de CC0 em Educação Matemática (SC1, RS1, RS2, RS3, RS4, RS6). Se compararmos com a carga horária total dos cursos de Pedagogia apresentados, que possuem cerca de nove semestres, nós inferiríamos que o tempo despendido para o debate de Educação Matemática ainda é pequeno. Por outro lado, esperamos que discussões sobre Educação Matemática não sejam objetos somente dos componentes específicos da área, mas que sejam diluídas em outros componentes curriculares de âmbito mais geral para a formação do pedagogo (Didática, Currículo, Estágios etc.).

Vale ainda destacar a ínfima Carga Horária Total nos cursos das Universidades paranaenses em CCO de Educação Matemática (30h e 60h). Mesmo considerando que 0 assunto seja discutido em outros componentes, compreendemos que a construção de um CCO realiza-se por princípios paradigmáticos de uma área, o que acarreta uma perda para a Educação Matemática. Ou seja, um CCO de didática, por exemplo, realizará uma interpretação sobre o ensino de Matemática a partir dos seus estudos. Embora pertinente, o lócus de leitura de mundo da Educação Matemática não entraria em funcionamento.

Outro ponto a se ressaltar consiste na localização dos CCO de Educação Matemática nos cursos de Pedagogia. Com exceção de RS4 que possui um CCO no início do curso, os demais concentram este estudo nos semestres medianos da Pedagogia. De modo geral, as propostas dos PPC caminham num percurso: (1) Componentes com cunho de fundamentos do campo da Pedagogia; (2) Componentes relativos a campos da Educação Infantil e disciplinas dos Anos Iniciais do Ensino Fundamental; e (3) Componentes de Práticas de Estágio e Trabalhos de Conclusão de Curso.

Quanto à divisão da Carga Horária, a maior parte dos CCO é composta por questões teóricas, sendo que as práticas não ultrapassam $40 \%$ de cada. No entanto, nem todos CCO tem carga horária prática, entre os 19 levantados apenas 10 a possuem.

Outro ponto analisado nos PPC foram as cargas horárias $(\mathrm{CH})$ presentes em Componentes Curriculares não Obrigatórias (CCnO) de Educação Matemática no curso de Pedagogia, conforme apresentado na tabela 3. 
Tabela 3 - Componentes Curriculares não Obrigatórios de Educação Matemática.

\begin{tabular}{llcc}
\hline PPC & \multicolumn{1}{c}{ CCn0 } & CH & CH total \\
\hline PR1 & Etnomatemática & $30 \mathrm{~h}$ & $30 \mathrm{~h}$ \\
PR2 & $\begin{array}{l}\text { CCn0 não evidenciados, embora o termo "optativa" apareça na grade curricular com Carga } \\
\text { Horária de 210 horas, a ocorrer nos dois últimos semestres. }\end{array}$ & \\
SC1 & Não possui. & & \\
SC2 & Não possui. & $60 \mathrm{~h}$ & \\
& Alfabetização e letramento em matemática & $60 \mathrm{~h}$ & $180 \mathrm{~h}$ \\
RS1 & Atividade matemática e representações semióticas & $60 \mathrm{~h}$ & \\
& Artigos em Educação Matemática & & \\
RS2 & Não possui & $45 \mathrm{~h}$ & \\
& Abordagem psicopedagógica da leitura, escrita e matemática & $45 \mathrm{~h}$ & $150 \mathrm{~h}$ \\
RS3 & Docência matemática: pensamento, linguagem e mundo & $60 \mathrm{~h}$ & \\
& Raciocínio lógico: desenvolvimento e avaliação & $60 \mathrm{~h}$ & $60 \mathrm{~h}$ \\
\hline RS4 & Matemática no Nível Fundamental & & \\
RS5 & Não possui & & \\
\hline RS6 & Não possui & & \\
\hline
\end{tabular}

Fonte: Construção dos autores.

No que tange aos CCnO em Educação Matemática, quatro dos dez cursos os oferecem (PR1, RS1, RS3, RS4), sendo que duas instituições do Rio Grande do Sul ofertam uma carga horária elevada com três disciplinas cada (RS1, RS3). Nos processos de elaboração dos CCn0, visualizamos uma aproximação entre as perspectivas de pesquisas e interesses dos docentes pertencentes aos cursos e as necessidades de aprofundamento para os discentes das instituições.

Em PR1, elencou-se o CCnO Etnomatemática, o que permite associarmos a um viés mais cultural em relação a Educação Matemática apresentada na Pedagogia desta universidade. Já RS1 apresentou três $\mathrm{CCnO}$, sendo que dois (Alfabetização e letramento em Matemática e Atividade matemática e representações semióticas) possuem aproximações com a prática docente na Educação Infantil e Anos Iniciais e um (Artigos em Educação Matemática) com a intencionalidade de inserir os discentes no percurso das pesquisas de Educação Matemática.

Por outro lado, em seus três CCnO, RS3 apresenta uma abordagem que evidencia uma relação estreita com a psicologia da aprendizagem, apoiando-se em tais estudos para provocar modos de pensar as práticas de ensino em Matemática. Por sua vez, RS4 elabora um CCnO com a intenção de reforçar os subsídios matemáticos e didáticos para o ensino nos Anos Iniciais do Ensino Fundamental, o que nos faz considerar a importância dada a Educação Matemática dessa faixa etária no PPC do curso.

Antes de adentrarmos no debate dos Componentes Curriculares de EMEl em si, alguns apontamentos que não pertencem aos itens anteriores sobressaíram na análise. 0 primeiro deles consiste na apresentação de componentes de conteúdo matemático em alguns PPC (PR1, SC2, RS1). PR1 e SC2 apresentam uma disciplina cada com o estudo de conteúdos matemáticos em nível de Ensino Médio, sendo, respectivamente, Matemática A (obrigatória, 30h) e Matemática Instrumental (optativa, 60h). RS1 e, ainda, SC2 evidenciam em seus PPC o componente Estatística Básica (obrigatória, 60h). Ao considerar a inserção de tais componentes, acreditamos que as propostas formativas procuram 
reforçar os conhecimentos matemáticos dos discentes da Pedagogia, uma vez que esta carência é reconhecida na literatura da área (CURI, 2004).

0 segundo ponto consiste que em três PPC emergiram a presença da Educação Matemática em outros componentes curriculares (RS3, RS6, PR2). Em diversas das referências bibliográficas de RS3 surgiram livros teóricos da área em questão. Já, em R6, nas descrições de algumas ementas de componentes de cunho mais prático, como estágio, é evidenciado o interesse de debates sobre 0 assunto. Por fim, PR2 possui 0 componente "Projetos Interdisciplinares para os Anos Iniciais" (120h) que possui uma discussão interdisciplinar, elencando a presença da Matemática no contexto. No entanto, vale ressaltar que esta última ação destacada em PR2 foca-se nos Anos Iniciais do Ensino Fundamental, não apresentando nenhum apontamento que nos leve a crer um debate sobre Educação Infantil.

\section{Fase 2: Componentes Curriculares de EMEI}

$\mathrm{Na}$ análise da segunda fase, trazemos novamente os Componentes Curriculares que possuem maior aproximação com EMEl, retirados da tabela 2.

Tabela 4 - Componentes Curriculares Obrigatórios de Educação Matemática com aproximação na Educação Infantil.

\begin{tabular}{|c|c|c|c|c|c|}
\hline PPC & CCO & SEM & $\mathrm{CH}$ & CHT & CHP \\
\hline PR1 & $\begin{array}{l}\text { Fundamentos teórico-metodológicos do Ensino da matemática na educação } \\
\text { infantil e anos iniciais do ensino fundamental }\end{array}$ & $5^{0}$ & $60 \mathrm{~h}$ & $60 \mathrm{~h}$ & Oh \\
\hline PR2 & Metodologia do Ensino da Matemática & $5^{0}$ & $30 \mathrm{~h}$ & $30 \mathrm{~h}$ & oh \\
\hline SC1 & Educação Matemática e Infância & $4^{0}$ & $72 \mathrm{~h}$ & $72 \mathrm{~h}$ & Oh \\
\hline SC2 & Matemática na infância I & $7^{0}$ & $30 \mathrm{~h}$ & $30 \mathrm{~h}$ & oh \\
\hline RS1 & Ensino de matemática I & $5^{0}$ & $60 \mathrm{~h}$ & $50 \mathrm{~h}$ & $10 \mathrm{~h}^{1}$ \\
\hline RS2 & Educação Matemática A & $5^{0}$ & $60 \mathrm{~h}$ & $45 \mathrm{~h}$ & $15 \mathrm{~h}$ \\
\hline RS3 & Educação Matemática I - A & $5^{0}$ & $75 \mathrm{~h}$ & $50 \mathrm{~h}$ & $25 \mathrm{~h}$ \\
\hline RS4 & Ensino-Aprendizagem, conhecimento e escolarização IV & $4^{0}$ & $60 \mathrm{~h}$ & $60 \mathrm{~h}$ & $\mathrm{Oh}$ \\
\hline RS5 & Metodologia do ensino em Matemática para crianças, jovens e adultos I & $5^{0}$ & $30 \mathrm{~h}$ & $30 \mathrm{~h}$ & $\mathrm{Oh}$ \\
\hline RS6 & Ensinar e Aprender Matemática I & $6^{0}$ & $60 \mathrm{~h}$ & $45 \mathrm{~h}$ & $15 \mathrm{~h}$ \\
\hline
\end{tabular}

Ao observarmos as nomenclaturas dos componentes, levantamos alguns apontamentos a partir de uma leitura flutuante dos termos que os compõem. A primeira questão é ressaltada em PR1 e RS5, que consiste na ausência de divisão entre Educação Infantil e Anos Iniciais do Ensino Fundamental. Essa prática permite não segmentar e/ou hierarquizar 0 conhecimento matemático na Educação Básica, mas, ao mesmo tempo, abre espaço para que práticas de ensino da Matemática nos Anos Iniciais prevaleçam em detrimento àquelas de Educação Infantil.

A segunda questão a ser evidenciada são os usos dos termos "Ensino de Matemática" (PR1, PR2, RS1, RS5) e "Educação Matemática" (SC1, RS2, RS3). Sobre o primeiro termo, acreditamos que 
são focalizadas as habilidades e práticas para o professor lecionar Matemática, já o segundo concentra-se nas discussões da construção do campo teórico-metodológico de Educação Matemática. Se extrapolarmos os estudos de Fiorentini e Lorenzato (2009), a conotação "Educação Matemática" torna-se mais viável para a formação do pedagogo, uma vez que advém de uma concepção que compreende a Matemática como um recurso empregado na educação para a formação dos sujeitos.

0 terceiro ponto apresentado nos CCO pauta-se na relação ensino e aprendizagem, ambos utilizados em duas nomenclaturas (RS4, RS6). Nessa relação são enfatizados tanto as práticas docentes em Matemática como os processos de apropriação deste conhecimento por parte dos alunos da Educação Básica. Vale ressaltar que a nomenclatura de RS6, nos possibilita associar, ainda, o CCO com a constituição do saber matemático e sua curricularização na escola.

0 último ponto relativo às nomenclaturas dos CCO está na aproximação com termo "Infância" (SC1, SC2). SC2 denomina seu componente de "Matemática na Infância", o que destaca as práticas sociais e cognitivas relativas ao pensamento matemático nessa etapa de vida. Já SC1 propõe a relação da infância com o campo teórico da Educação Matemática, possibilitando as emergências de questões teórico-metodológicas e de pesquisa dessa área.

Já no que tange a carga horária, percebemos as ausências das atividades práticas nos contextos dos CCO, uma vez que somente quatro dos dez componentes as possuem. No contexto do componente, é importante que os encaminhamentos práticos sejam planejados e "seu acontecer deve se dar desde o início da duração do processo formativo e se estender ao longo de todo o seu processo" (BRASIL, 2001, p. 2). Nesse sentido, defendemos a presença de carga horária prática em tais CCO.

No que ser refere às ementas dos CCO de EMEI, elencamos alguns núcleos comuns para debate:

- Núcleo 1 - Educação Infantil sempre associada aos Anos Iniciais (PR1, PR2, RS1, RS5): nessas ementas, encontramos ações voltadas somente para os Anos Iniciais, mas nenhuma ação ligada apenas com a Educação Infantil. Os poucos momentos em que a Educação Infantil emerge estão associados com os Anos Iniciais. As práticas que permeiam os dois níveis são: processos de ensino e aprendizagem de conteúdos básicos de matemática (PR1, RS1) e fundamentos teóricos e metodológicos do ensino de matemática (PR2, RS5);

- Núcleo 2 - Essencialmente ligada com Educação Infantil (SC1, SC2, RS6): dos CCO apresentados, SC1 apresenta uma abordagem mais genérica, ressaltando apenas que abordará a "Matemática e suas relações com a infância" (SC1). Já SC2 e RS6 são explícitos na sua atuação. Ambas apontam questões relativas aos conceitos matemáticos e as abordagem didático-metodológicas na Educação Infantil.

Os conceitos sobressalientes em SC1 são o "conceito de número e suas estruturas aditivas" (SC1), bem como "espaços, tempos, quantidades, relações e transformações" (SC1). Já em RS6 emergem blocos de conteúdos - "Números e Operações, Grandezas e Medidas, Espaço e Forma e algumas ideias de Tratamento da Informação" (RS6). Tanto SC1 quanto RS6 descrevem uma aproximação com os Referenciais Curriculares de Educação Infantil (BRASIL, 1998), mas ainda não incorporaram a BNCC (BRASIL, 2017), devido a sua recente construção.

No que tange às abordagens metodológicas, SC2 ressalta a necessidade de exploração do entorno "por meio de experiências [e a] análise e produção didática de materiais" (SC1). Algo semeIhante a RS6, que propõe "vivência de situações [...] e [produção e debate de] recursos didáticos e metodológicos para a Educação Infantil” (RS6).

- Núcleo 3 - Presença da Alfabetização Matemática (SC2, RS2): entre os CC0 analisados somente SC2 e RS2 apresentam o debate sobre 0 conceito de alfabetização matemática. Porém, não há nenhum indício nos mesmos de discussões sobre os termos letramento, numeracia ou numeramento, 
também vigentes como possibilidades de debate. Nesse sentido, consideramos que, para uma inserção do contexto social da Matemática nos componentes, o uso dessas demais conceituações possibilitaria ações formativas mais profícuas (MORAES, 2018). Essa ideia na formação inicial do pedagogo conduziria ainda a associações com os estudos de componentes relativos ao ensino da língua portuguesa presentes no curso.

- Núcleo 4 - Presença da ludicidade (PR1, RS1, RS5, RS6): quatro CC0 enfatizam a relação com abordagens que tragam o lúdico para o contexto de sala de aula. Estes estão contemplados em discussões sobre jogos matemáticos (PR1, RS5, RS6), brincadeiras (RS1, RS6), brinquedos (RS5) e materiais manipuláveis (RS6). Nesse sentido, a ludicidade se apresenta nos CCO amparada em materiais ou perspectivas metodológicas que visam intervenção e promoção do pensamento matemático nas crianças;

- Nível 5 - Ênfase na psicologia da aprendizagem (RS2, RS4): dois ementários de CCO apresentaram forte conotação com as teorias de aprendizagem. RS2 intenta analisar tanto as concepções sobre a aprendizagem matemática na infância quanto as suas decorrências para 0 ensino (RS2). Já RS4 fundamenta a sua ementa de maneira integral nos estudos piagetianos e vigotskyanos, apresentando e discutindo teorias e processos de aprendizagem vinculados a tais autores.

A partir da observação supracitada, nota-se que mesmo com intencionalidades de estudo sobre a Educação Matemática na Educação Infantil, os CCO tomam caminhos diversos no contexto da Pedagogia e, até mesmo, plurais no interior de cada componente.

Já quanto às referências básicas relativas à Educação Infantil nos CCO de EMEl, identificamos quatro grupos:

- Grupo 1 - Ausência de referências específicas de EMEI (PR2, SC1, RS3, RS4, RS5): estes CCO apresentaram referências baseadas na psicologia, na educação ou, até mesmo, na Educação Matemática em si. Porém, não houve indicativos de materiais que abordem a Matemática na Educação Infantil.

- Grupo 2 - Ênfase nas brincadeiras e jogos (PR1, SC2, RS6): três CCO apresentam livros com a intenção de trabalhar brincadeiras para 0 ensino da Matemática na Educação Infantil. Os materiais são: "A Matemática através de brincadeiras e jogos" (ARANÃ0, 2011) (PR1), "Brincar e jogar: enlaces teóricos e metodológicos no campo da Educação Matemática" (MUNIZ, 2010) (SC2), "Brincadeira infantis nas aulas de Matemática" (SMOLE; DINIZ; CÂNDIDO, 2000) (SC2, RS6).

- Grupo 3 - A presença do conhecimento matemático na Educação Infantil (SC2, RS1, RS2, RS6): em quatro CCO são elencados livros que ensejam debater Educação Matemática para a Educação Infantil, são eles: "Encontros iniciais com a matemática: contribuições à Educação Infantil" (DUHALDE, 1998) (RS1), "A Matemática na Educação Infantil: a teoria das inteligências múltiplas na prática escolar" (SMOLE, 1996) (SC2), "Educação Infantil e percepção matemática" (LORENZATO, 2006) (RS2, RS6).

- Grupo 4 - Inserção de documentos oficiais (RS6): somente RS6 apresentou em seu CCO 0 debate de documentos norteadores, no caso o "Referencial Curricular Nacional para a Educação Infantil" (BRASIL, 1998). Essa ausência torna-se perigosa, uma vez que os debates curriculares podem não pertencer aos CCO em questão.

De modo geral, percebemos poucas referências que tratem Educação Matemática para a Educação Infantil. No entanto, vemos uma apropriação de outras referências para um debate específico, como é possível ver nas ausências destacadas. Outro ponto é a crescente questão das brincadeiras e jogos para a Educação Infantil, que parecem ser o caminho tomado pela maioria dos CCO. 
Consideramos ainda pertinente estabelecer uma relação entre os CCO de EMEl com as cargas horárias teóricas e práticas dos CCO de Educação Infantil que ocorrem antes, durante e depois do semestre que o primeiro componente citado acontece. No levantamento das cargas horárias, obtemos a seguinte tabela:

Tabela 5 - Relação entre CCO de EMEI e cargas horárias de CCO de Educação Infantil.

\begin{tabular}{|c|c|c|c|c|c|c|}
\hline \multirow[b]{2}{*}{ PPC } & \multicolumn{3}{|c|}{ Carga Horária Teórica } & \multicolumn{3}{|c|}{ Carga Horária Prática } \\
\hline & $\begin{array}{l}\text { Antes de } \\
\text { CCO de EMEI }\end{array}$ & $\begin{array}{c}\text { Durante } \\
\text { CCO de EMEI }\end{array}$ & $\begin{array}{l}\text { Após de } \\
\text { CCO de EMEI }\end{array}$ & $\begin{array}{c}\text { Antes de } \\
\text { CCO de EMEI }\end{array}$ & $\begin{array}{c}\text { Durante } \\
\text { CCO de EMEI }\end{array}$ & $\begin{array}{c}\text { Após de } \\
\text { CCO de EMEI }\end{array}$ \\
\hline PR1 & $210 \mathrm{~h}$ & Oh & Oh & $45 \mathrm{~h}$ & Oh & Oh \\
\hline PR2 & $150 \mathrm{~h}$ & Oh & Oh & Oh & Oh & Oh \\
\hline SC11 & $144 \mathrm{~h}$ & $162 \mathrm{~h}$ & $252 \mathrm{~h}$ & $\mathrm{Oh}$ & Oh & Oh \\
\hline SC2 & $105 \mathrm{~h}$ & Oh & Oh & $45 \mathrm{~h}$ & $0 \mathrm{~h}$ & Oh \\
\hline RS1 & $60 \mathrm{~h}$ & $60 \mathrm{~h}$ & $\mathrm{Oh}$ & $15 \mathrm{~h}$ & $15 \mathrm{~h}$ & $\mathrm{Oh}$ \\
\hline RS2 & $30 \mathrm{~h}$ & $45 \mathrm{~h}$ & $45 \mathrm{~h}$ & $\mathrm{Oh}$ & $\mathrm{Oh}$ & $15 \mathrm{~h}$ \\
\hline RS3 & $55 \mathrm{~h}$ & Oh & Oh & $35 \mathrm{~h}$ & Oh & Oh \\
\hline RS4 & 45 & $45 \mathrm{~h}$ & $45 \mathrm{~h}$ & $30 \mathrm{~h}$ & $30 \mathrm{~h}$ & $30 \mathrm{~h}$ \\
\hline RS51 & 210 & $30 \mathrm{~h}$ & $60 \mathrm{~h}$ & Oh & Oh & Oh \\
\hline RS6 & $75 \mathrm{~h}$ & Oh & $45 \mathrm{~h}$ & $45 \mathrm{~h}$ & Oh & $15 \mathrm{~h}$ \\
\hline
\end{tabular}

Nota-se que a carga horária em CCO de Educação Infantil encontra-se, em sua maioria, antes do semestre letivo em que é ofertado CCO de EMEI. Assim, consideramos que os discentes quando cursam o componente de EMEl já possui conhecimento teórico sobre Educação Infantil, o que possibilita um olhar mais crítico com o mesmo. Vale destacar a grande carga horária de CCO de Educação Infantil de SC1, que atinge 558h (antes, durante e após de CCO de EMEI).

Por fim, a investigação analisou a relação entre os CCO de EMEl e os componentes relativos à Estágio Supervisionado na Educação Infantil, considerando que 0 ideal seria a sua realização após, uma vez que 0 aluno teria fundamentos para prática e análise da ação docente na Educação Infantil. A partir da análise, notou-se que somente PR2 realiza o estágio antecedendo CCO de EMEl, o que nos faz crer que a relação entre esses componentes não é pensada no PPC da instituição.

\section{CONSIDERAÇÕES FINAIS}

A pesquisa aqui realizada intencionava analisar a relação de componentes curriculares obrigatórios de Educação Matemática em cursos de Pedagogia presenciais das Universidades Federais da região Sul do país com o debate sobre Educação Infantil. Em nenhum momento defendeu-se a criação de componentes curriculares de Educação Matemática específicos para a Educação Infantil, mas desejou-se desvelar alguns elementos sobre o tema presente no curso de Pedagogia. No entanto, reforçamos a ideia que pela égide de não hierarquizar e segmentar as duas etapas de ensino, 
Educação Infantil e Anos Iniciais, muitas propostas de formação de docentes podem resultar em um abandono do debate da Educação Matemática na Educação Infantil.

Perante a pesquisa, alguns pontos ficaram mais evidentes na composição dos componentes: 0 foco sobressaliente de práticas caracterizadas como promotoras de ludicidade, o papel significativo da psicologia da aprendizagem, a ausência em alguns componentes de referências bibliográficas básicas no campo da Infância e Educação Matemática e dos documentos oficiais e, ainda, a construção de um vínculo quase indissolúvel entre Educação Infantil e Anos Iniciais.

Com os resultados aqui apresentados, esperamos que novos estudos sejam potencializados, capazes de pensar novas possibilidades para a Educação Infantil na Educação Matemática, bem como significações na elaboração de componentes curriculares nos cursos de Pedagogia no Brasil.

\section{REFERÊNCIAS}

AGAMBEN, G. Infância e história. Buenos Aires: Adriana Hidalgo, 2001.

APPOLINÁRIO, F. Dicionário de metodologia científica: um guia para a produção do conhecimento científico. São Paulo, Atlas, 2009.

ARANÃO, I. D. A matemática através das brincadeiras e jogos. Campinas, SP. Papirus, 2011.

ARIĖS, P. História Social da Criança e da Família. Rio de Janeiro: LTC, 1978.

BRASIL. Base Nacional Comum Curricular. 2017. Disponível em: https://bit.ly/3m3f5zh. Acesso em: 15 de junho de 2020.

. Diretrizes Curriculares Nacionais para a Educação Infantil. Brasília, DF, 2010. Disponível em: https://bit.ly/ 3khGPQ2. Acesso em: 15 de junho de 2020.

. Referencial curricular nacional para a Educação Infantil. Ministério da Educação e do Desporto, Secretaria de Educação Fundamental. Brasília: MEC/SEF, 1998.

Resolução $\mathrm{CNE} / \mathrm{CP} \mathbf{n}^{0}$ 02, de $\mathbf{1}^{0}$ de julho de 2015. Define as Diretrizes Curriculares Nacionais para a formação inicial em nível superior (cursos de licenciatura, cursos de formação pedagógica para graduados e cursos de segunda licenciatura) e para a formação continuada. Diário Oficial da União, Brasília, 2 jul 2015.

. Diretrizes Curriculares Nacionais e Base Nacional Comum para a Formação Inicial e Continuada de Professores da Educação Básica. Resolução nº 2, de 20 de dezembro de 2019. (DOU no 247, 23.12.2019, Seção 1, p.115).

Parecer ñ 028, de 02 de outubro de 2001. Dá nova redação ao Parecer CNE/CP 021/2001, que estabelece a duração e a carga horária dos cursos de formação de Professores da Educação Básica, em nível superior, curso de licenciatura, de graduação plena. Brasília/DF, 02/10/2001.

CURI, E. A Matemática e os Professores dos Anos Iniciais. São Paulo: Musa Editora, 2005. 
Formação de professores polivalentes: uma análise do conhecimento para ensinar Matemática e de crenças e atitudes que interferem na constituição desses conhecimentos. 2004. 278 f. Tese (Doutorado em Educação Matemática) - Faculdade de Educação Matemática, PUCSP, São Paulo, 2004.

DUHALDE, M. E. Encontro iniciais com matemática: contribuições a educação infantil. Porto Alegre: Artes Médicas, 1998.

FIORENTINI, D. Rumos da pesquisa brasileira em educação matemática: 0 caso da produção científica em cursos de pós-graduação. 1994. 414f. Tese (Doutorado em Educação) - Universidade Estadual de Campinas, Campinas, 1994

; LORENZATO, S. Investigação em educação matemática: percursos teóricos e metodológicos. Campinas, SP: Autores Associados, 2009.

KOHAN, W. O. A infância da educação: 0 conceito devir-criança. Lugares da infância: filosofia. Rio de Janeiro: DP\&A, p. 51-68, 2004.

KRAMER, S. A Política do Pré-Escolar no Brasil: a arte do disfarce. 7. Ed. São Paulo: Cortez, 2003.

LORENZATO, S. Educação Infantil e percepção matemática. Campinas: Autores Associados, 2006.

LÜDKE, M.; ANDRÉ, M.E.D.A. Pesquisa em educação: abordagens qualitativas. São Paulo, EPU, 1986.

MORAES, J. C. P. Insubordinação, Invenção e Educação: a produção de reflexões por meio do espaço na formação inicial docente em pedagogia. Tese (Doutorado em Educação). Faculdade de Educação da Universidade de São Paulo, 2018.

MUNIZ, C. A. Brincar e jogar: enlaces teóricos e metodológicos no campo da educação matemática. Autêntica: Belo Horizonte, 2010.

PERRENOUD, P. Formar professores em contextos sociais em mudança. Revista Brasileira de Educação, v. 12, p. 5-19, 1999.

SBEM. Grupo de Trabalho 01 - Matemática na Educação Infantil e Anos Iniciais do Ensino Fundamental. Disponível em: https://bit.ly/3m8fd0e. Acessado em 15/06/2020.

SCHON, D. Educando o Profissional Reflexivo: um novo design para o ensino e aprendizagem. Trad. Roberto Cataldo Costa. Porto Alegre: Artes Médicas Sul, 2000.

SHULMAN, L. S. Knowlege and teaching: foundations of the new reform. Harvard Educational Review, v. 57, n. 1, p. 1-22, 1987.

SMOLE, K.C. A matemática na educação infantil: a teoria das inteligências múltiplas na prática escolar. Porto Alegre: Artes Médicas, 1996. 
; DINIZ, M. I.; CÂNDIDO, P. Brincadeiras infantis nas aulas de matemática. Porto Alegre: Artes Médicas, 2000. 84 p.

TARDIF, M. Saberes docentes e formação profissional. Petrópolis, RJ: Vozes, 2002.

VILLANI, A.; PACCA, J. L. A. Construtivismo, conhecimento científico e habilidade didática no ensino de ciências.

Revista da faculdade de Educação, v. 23, n. 1-2, 1997.

ZABALZA, M. A. Qualidade em Educação Infantil. Porto Alegre: Artmed, 1998.

RECEBIDO EM: 17 jun. 2020

CONCLUÍDO EM: 24 ago. 2020 
